Proc. of JSCE,

No. 189, May 1971

\title{
TIME HEADWAY DISTRIBUTION OF TRAFFIC FLOW
}

\author{
By Masahiko KATAKURA
}

Arrival distribution of vehicles is one of the basic characteristics of traffic flow. Since average time headway is inversely proportional to the traffic volume it has been considered as an approach of the study of traffic capacity. Arrival distribution is essential to deal with the traffic flow stochastically in the problems such as queing problems of crossing or merging traffic, and various traffic simulation.

The paper deals mainly with congested traffic flow which causes so many traffic problems. The objects of this study is to obtain and analyse the characteristics of actual traffic headway distributions and to find theoretical distribution models which fit well to them.

Several field observations were carried out and a theoretical distribution of traffic headway is proposed based on the observed data. The theoretical distribution fits very well to the actual ones.

\section{BRIEF REVIEW ON PREVIOUS STUDIES ${ }^{3) \text {, 4) }}$}

Many reports ${ }^{13,2), 5)}$ have showed that distribution of arrivals in short period could possibly be represented by Poisson distribution. Adams showed that the Poisson distribution was applicable to the distribution of vehicle arrivals in 1936, and since then Poisson distribution has been extensively employed in many theories of traffic flow.

If the distribution of arrivals in short period is Poisson, the headway between successive arrivals should be distributed in the form of negative exponential distribution; therefore, negative exponential distribution has been often used to handle the time headway distribution problems.

In actual traffic flow, however, the assumption of Poisson arrival can be well applied only when traffic volume is small. There are two limiting factors in applying negative exponential distribution to the headway distribution. Firstly, negative exponential distribution spreads over entire range of time head-

* Research Associate, Department of Civil Engineering, Tokyo Institute of Technology, Tokyo way from zero to infinity and probability density is maximum at $t=0$, while there in fact exists an minimum finite headway since a vehicle has a finite length and finite speed. Secondly, it has also observed that as traffic volume increases platoons are formed and consequently headway tends to concentrate within a certain short range.

Various modifications of the basic Poisson distribution have been proposed to compensate these disagreements. For the first problem, Gerlough ${ }^{6}$ proposed the shifted exponential distribution in which the exponential curve is shifted by a certain distance away from the origin along the time axis. Haight $^{7)}$ mentioned that the Erlang distribution, or Pearson's type III distribution, could be applied.

This distribution is a generalization of negative exponential distribution and in applying the distribution the very small headway is improbable since the curve pass through the origin.

The probability density function of Erlang distribution is written as :

$$
f(t)=(\lambda K)^{K} t^{K-1} \exp (-\lambda K t) /(K-1) !
$$

where $K$ and $\lambda$ are parameters of the probability density function and $K$ is a positive integer which is called a phase of Erlang distribution. It is obvious that when $K$ is unity the distribution is identical to exponential distribution (random arrival), and when $K$ approaches to infinity it approaches to unit distribution (regular arrival). Haight says that this theoretical distribution can fit a variety of field data through adopting suitable $K$ values.

While a more generalised form of gumma probability density function ${ }^{8}$ ) could of course be used and would fit better, computation becomes complicated and still not so much improved as compared with Erlang distribution.

For the second problem, the platooning effect of traffic, a composite exponential distribution was first proposed by Shuhl ${ }^{9}$. He pointed out a traffic stream could be composed of a combination of free-moving and constrained vehicles each of which conforms to Poisson distribution. 
The equation of the composite distribution in this case is

$$
\begin{aligned}
p(h \geq t)= & (1-a) \exp \left(-(t-\lambda) /\left(T_{1}-\lambda\right)\right) \\
& +a \exp \left(-(t-\tau) /\left(T_{2}-\tau\right)\right) \cdots(2)
\end{aligned}
$$

in which

$p(h \geq t)=$ probability of a headway $h$, greater than or equal to time $t$;

$a=$ proportion of the traffic stream in constrained group;

$1-a=$ proportion of the traffic stream in freemoving group;

$T_{1}=$ average headway of free-moving vehicles

$T_{2}=$ average headway of constrained vehicles

$\lambda=$ minimum headway of free-moving vehicles

$\tau=$ minimum headway of constrained vehicles

This distribution is illustrated to compare with data observed on two-lane urban streets in Highway Capacity Manual $^{10)}$ but it seems not to fit so well in the range of short headways as far as the figure in the Manual concerned. It does not seem reasonable in addition that the constrained group of traffic flow have exponentially distributed headways. Haight also showed various compound gap distributions in his book ${ }^{11)}$.

Generally, density function of such distribution as the combination of two phenomena can be written in the following form,

$$
g(t)=(1-a) g_{L}(t)+a g_{F}(t)
$$
where

$g(t)=$ probability density function of time headway of all traffic

$g_{L}(t)=$ probability density function of time headway of free-moving vehicles (leaders)

$g_{F}(t)=$ probability density function of time headway of constrained vehicles (followers)

$a=$ proportion of the constrained vehicles in the total traffic

$1-a=$ proportion of the free-moving vehicles

Although this relationship may be understood intuitively, there might be some doubt if $a$, in terms of the proportion of vehicular volumes, could be directly used in the equation of probability density functions. It will be shown after in the appendix that this equation can be proved generally from the relationship between counting distribution and gap distribution.

Free-moving vehicles are either isolated vehicles or head vehicles of platoons, thus they are reffered as leaders while constrained vehicles are called followers.

There are two difficulties in applying this theoretical distribution to actual headway distribution. What kind of distribution should be applied for $g_{L}$ $(t)$ and $g_{F}(t)$, and how the values of $a$, proportion of platoon, could be obtained?

Since leaders are free-moving vehicles truncated negative exponential distribution can also be applied to their headways. In adopting the composite exponential distribution, the truncated exponential distribution can also be applied to followers' headways. Since headways of followers tend to be more or less alike with each other, distributions other than negative exponential might be applied. Prof. Takada ${ }^{12)}$ proposed phase of 6 Erlang distribution.

The second questions is more difficult because criteria on which leaders and followers should be distinguished from each other have not been established yet. They can not be clearly distinguished in actual traffic flow through conventional observations since vehicles are always changing their state from leader to follower.

In the above mentioned compound distribution platooning is represented by the proportion of followers which are defined as those headways are less than a certain empirical value. In this report, however, platooning factor $a$ is not determined by classifying vehicles into two categories, followers and leaders, but is induced as a result of fitting a theoretical distribution which composed of two Erlang distributions of different $K_{s}{ }^{\prime}$ to the actual ones, since this report is interested in obtaining a theoretical distribution.

\section{CHARACTERISTICS OF OBSERVED HEADWAYS}

\section{(1) Field observations}

Table 1 shows the observations carried out for this study. The time interval of vehicles passing at a point were measured from photographs which were taken at a constant interval by a $35 \mathrm{~mm}$ motordriven camera and a $16 \mathrm{~mm}$ cine camera.

Observations were made when traffic was heavy since the author is mainly interested in heavy traffic. The influence of traffic composition was not regarded because the headway distribution characteristics of flows of a particular kind of vehicles cannot be deduced from actual data and in fact majority of vehicles observed were passenger cars. An observation at Yokohama By-pass was made when the traffic density was over the critical density and stop-andgo condition was observed for a few moment. Full capacity condition at peak period was observed at Tokyo Expressway Route 4.

\section{(2) Results of analysis}

The time headway characteristics obtained from the observations on actual traffic flow are as follows;

a) Coefficient of variance of headway distributions 
Table 1 Observations

\begin{tabular}{|c|c|c|c|}
\hline Date & Road & Instrument & Road and Traffic Condition \\
\hline $\begin{array}{l}10 \text { th. Dec. } 1964 \\
\text { p.m. } 1: 20 \sim 1: 50\end{array}$ & $\begin{array}{l}\text { Tokyo Expressway } \\
\text { Route No. } 1\end{array}$ & $\begin{array}{l}35 \mathrm{~mm} \text { Motor Driven } \\
\text { Camera }\end{array}$ & $\begin{array}{l}\text { Level, Straight, Devided 4-lane Urban Expressway. } \\
\text { Lane width }=3.25 \mathrm{~m}\end{array}$ \\
\hline $\begin{array}{l}25 \text { th. Dec. } 1964 \\
\text { a.m. } 11: 05 \sim 11: 40\end{array}$ & $\begin{array}{l}\text { National Route } 14 \\
\text { Chiba Highway }\end{array}$ & $"$ & Level, Straight, 2-lane Highway Roadway width $=9 \mathrm{~m}$ \\
\hline $\begin{array}{l}3 \text { rd. Jan. } 1965 \\
\text { p.m. } 3: 30 \sim 4: 20\end{array}$ & Meishin Expressway & $"$ & Level, Straight, Devided 4-lane Freeway. Lane width $=3.60 \mathrm{~m}$ \\
\hline $\begin{array}{l}\text { 1 st. Aug. } 1965 \\
\text { a.m. } 9: 30 \sim 10: 00\end{array}$ & Yokohama By-pass & $16 \mathrm{~mm}$ Cine Camera & $\begin{array}{l}\text { Level, almost Straight, Undevided 4-lane Highway. } \\
\text { Lane width }=3.25 \mathrm{~m} \text { High Density Condition }\end{array}$ \\
\hline $\begin{array}{l}11 \text { th. May } 1967 \\
\text { a.m. } 8: 10 \sim 9: 20\end{array}$ & $\begin{array}{l}\text { Tokyo Expressway } \\
\text { Route No. } 4\end{array}$ & & $\begin{array}{l}\text { Downgrade ( } 3 \%) \text {, Straight, Devided 4-lane Urban Expressway. } \\
\text { Lane width }=3.25 \mathrm{~m} \text { Full Capacity Condition }\end{array}$ \\
\hline $\begin{array}{l}15 \text { th. July } 1969 \\
\text { a.m. } 9: 30 \sim 10: 30\end{array}$ & $\begin{array}{l}\text { Tokyo Expressway } \\
\text { Ring Route }\end{array}$ & $\begin{array}{l}16 \mathrm{~mm} \text { cine camera } \\
\text { Event Oscilograph }\end{array}$ & $\begin{array}{l}\text { Level, Straight, Devided 4-lane Urban Expressway. } \\
\text { Lane width }=3.25 \mathrm{~m}\end{array}$ \\
\hline
\end{tabular}

If traffic flow is random the headway distribution can be represented by negative exponential function and standard deviation is equal to the mean and then the coefficient of variance is equal to unity. In the actual traffic, however, outer lane (1 st lane) and inner lane ( 2 nd lane) of a 4 -lane highway have different characteristics. In the outer lane the coefficient of variance is generally less than 1 and is about 0.7 to 0.8 . In the inner lane, on the other hand, it is more than 1 and about 1.2 to 1.3 . When traffic volume increases the coefficient of variance of inner lane becomes also less than 1 as observed at Tokyo Expressway Route 4. When stop-and-go condition occures at the over critical density the coefficient of variance increases and exceeds 1 even in the outer lane in the observation at Yokohama By-pass.

In the observation on a two lane highway at National Route 14 the coefficient of variance exceeds 1 also. Perhaps the adjacent traffic signal seems to influence the headway distribution, although observation site was located as far as possible from the signalised intersection.

b) The mode and the minimum value of headway distribution

The modes (most frequent values) appear between 1.5 seconds and 2.0 seconds for both outer lane traffic of 4-lane highways and a 2-lane highway as seen in Table 2. They are between 0.5 to 1.0 seconds for inner lane traffic of 4lane highways.

Abscissa of the histogrums of headway distribution is divided tnto 0.3 seconds in Fig. 1 in order to determine the modes more accurately instead of 0.5 seconds. The modes are 1.5 to 1.7 seconds in the outer lanes and 0.9 to 1.1 seconds in the inner lanes.
The above mentioned results on modes may apply to almost all types of roads and all traffic conditions except over-critical density condition. The difference in modes of headway distribution between inner and outer lanes at ordinary conditions disappears when traffic density becomes over critical as shown in Fig. 2 (d) and 2 (c), the examples of Yokohama By-pass or Tokyo Expressway Route 4. The figures also show that the headways of the traffic in inner lanes tend to concentrate around the modes more sharply than the outer lane traffic.

As to the minimum time headway, 0.1 seconds
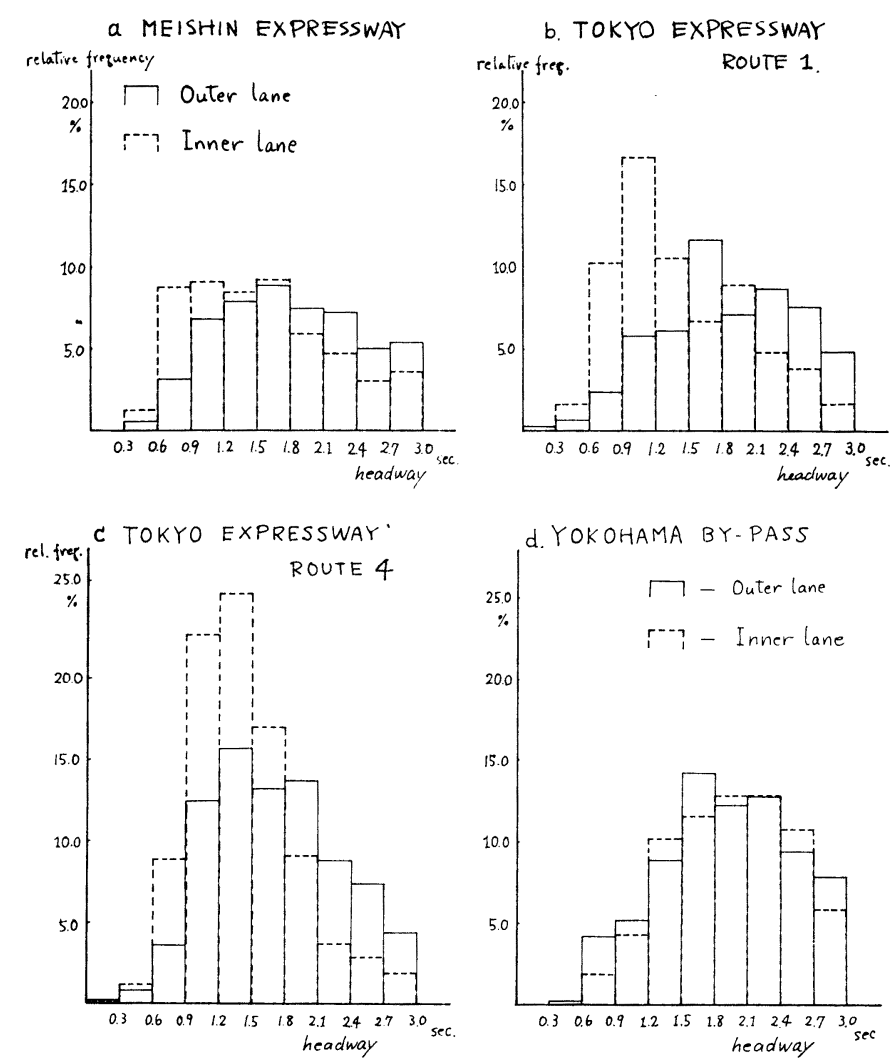

Fig. 1 The Histogrums of Headway Distribution

Divided into $0.3 \mathrm{sec}$

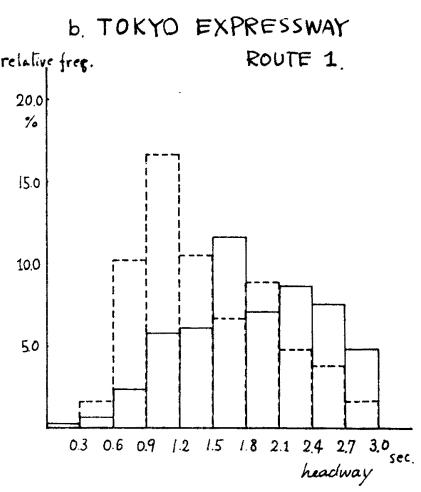


Table 2 Observed Characteristics of Time Headway

\begin{tabular}{|c|c|c|c|c|c|c|c|c|c|c|}
\hline \multicolumn{2}{|l|}{ Road \& Lane } & $\underset{(\mathrm{sec})}{T}$ & $\begin{array}{l}\text { Size of } \\
\text { Samples }\end{array}$ & $\begin{array}{l}\text { Mean } \\
(\mathrm{sec})\end{array}$ & $\begin{array}{c}\text { Variance } \\
\left(\sec ^{2}\right)\end{array}$ & $\begin{array}{l}\text { S.D. } \\
(\mathrm{sec})\end{array}$ & C.V. & $\begin{array}{l}\text { Median } \\
(\mathrm{sec})\end{array}$ & $\frac{\text { Median }}{\text { Mean }}$ & $\begin{array}{l}\text { Mode } \\
(\mathrm{sec})\end{array}$ \\
\hline Meishin Expwy & No. 1 & 22 & 453 & 2.94 & 3.93 & 1.98 & 0.67 & 2.2 & 0.75 & $1.0 \sim 1.4$ \\
\hline Down Outer & No. 2 & 16 & 332 & 2.92 & 4.87 & 2.21 & 0.76 & 2.1 & 0.72 & $1.5 \sim 1.9$ \\
\hline Meishin Expwy & No. 1 & 22 & 299 & 4.43 & 8.88 & 2.99 & 0.68 & 3.5 & 0.79 & $1.5 \sim 1.9$ \\
\hline Up Outer & No. 2 & 16 & 225 & 4.28 & 11.82 & 3.44 & 0.80 & 3.2 & 0.75 & $1.5 \sim 1.9$ \\
\hline Meishin Expwy & No. 1 & 22 & 316 & 4.21 & 26.49 & 5.17 & 1.22 & 2.0 & 0.47 & $0.5 \sim 0.9$ \\
\hline Down Inner & No. 2 & 16 & 222 & 4.30 & 36.67 & 6.06 & 1.40 & 1.9 & 0.42 & $1.0 \sim 1.4$ \\
\hline Meishin Expwy & No. 1 & 22 & 168 & 7.90 & 86.64 & 9.31 & 1.18 & 3.7 & 0.47 & $0.5 \sim 0.9$ \\
\hline Up Inner & No. 2 & 16 & 120 & 7.68 & 91.39 & 9.57 & 1.24 & 3.2 & 0.42 & $1.0 \sim 1.4$ \\
\hline Tokyo Expwy & Outer & 12 & 217 & 3.22 & 6.22 & 2.49 & 0.77 & 2.4 & 0.75 & $1.5 \sim 1.9$ \\
\hline Rt. 1 Down & Inner & 12 & 220 & 3.16 & 21.03 & 4.59 & 1.42 & 1.7 & 0.54 & $1.0 \sim 1.4$ \\
\hline Yokohama & Outer & 19 & 406 & 2.87 & 11.49 & 3.39 & 1.18 & 2.2 & 0.77 & $1.5 \sim 1.9$ \\
\hline Bypass Down & Inner & 19 & 372 & 3.14 & 14.44 & 3.80 & 1.20 & 2.2 & 0.70 & $1.5 \sim 1.9$ \\
\hline National & Down & 24 & 398 & 3.55 & 17.04 & 4.13 & 1.16 & 2.05 & 0.58 & $1.5 \sim 1.9$ \\
\hline Route 14 & Up & 24 & 365 & 3.76 & 21.47 & 4.63 & 1.23 & 2.10 & 0.56 & $1.5 \sim 1.9$ \\
\hline Tokyo Expwy & No. 1 & 6 & 203 & 1.83 & 0.72 & 0.85 & 0.46 & 1.6 & 0.87 & $1.0 \sim 1.4$ \\
\hline Route $4 \mathrm{Up}$ & No. 2 & 25 & 617 & 2.40 & 3.32 & 1.82 & 0.76 & 1.8 & 0.75 & $1.0 \sim 1.4$ \\
\hline Outer lane & No. 3 & 7 & 158 & 2.60 & 3.63 & 1.91 & 0.73 & 1.9 & 0.73 & $1.0 \sim 1.4$ \\
\hline Tokyo Expwy & No. 1 & 6 & 233 & 1.69 & 0.19 & 0.44 & 0.28 & 1.5 & 0.94 & $1.0 \sim 1.4$ \\
\hline Route $4 \mathrm{Up}$ & No. 2 & 25 & 907 & 1.65 & 2.50 & 1.58 & 0.96 & 1.4 & 0.85 & $1.0 \sim 1.4$ \\
\hline Inner lane & No. 3 & 7 & 210 & 1.97 & 3.95 & 1.99 & 1.01 & 1.4 & 0.71 & $1.0 \sim 1.4$ \\
\hline Tokyo Expwy & No. 1 & 24 & 542 & 2.69 & 3.58 & 1.89 & 0.70 & 2.1 & 0.78 & $1.5 \sim 1.9$ \\
\hline Ring Rt. Outer & No. 2 & 24 & 557 & 2.65 & 3.29 & 1.81 & 0.68 & 2.1 & 0.79 & $1.0 \sim 1.4$ \\
\hline Tokyo Expwy & No. 1 & 24 & 634 & 2.30 & 3.72 & 1.93 & 0.84 & 1.7 & 0.74 & $1.0 \sim 1.4$ \\
\hline Ring Rt. Inner & No. 2 & 24 & 706 & 2.10 & 2.88 & 1.70 & 0.81 & 1.6 & 0.76 & $1.0 \sim 1.4$ \\
\hline
\end{tabular}

$T=$ Observed Period ; S.D. $=$ Standard Deviation ; C.V. $=$ Coefficient of Variance

headway was observed but it is thought to be due to either observation error or a special case where the following car was changing the lane. Headways less than 0.5 seconds were found quite seldom in the observations. The minimum headway could be considerd, therefore, to be 0.4 to 0.5 seconds, even though the value may be longer, of course, for slower speed traffic as observed at Yokohama Bypass and National Route 14.

c) Median of headway distribution

The time headway distribution curves show that the median values are always smaller than mean values such as in the case of modes. The medians are about $50 \%$ and between $70 \%$ and $80 \%$ of the mean values for inner and outer lane traffic respectively in moderate traffic volume.

\section{(3) Conclusion}

The results of headway characteristics described above are summarized in Table 2 .

\section{PROPOSED THEORETICAL DISTRIBUTION}

The author proposes a theoretical headway distribution which fits well to the actual ones based on the observation results described above.

The distribution is a composite of two different distributions which is based on the assumption that a traffic flow is composed of free flow (leaders) and constrained flow (followers) as prescribed Equation (3) which is

$$
g(t)=(1-a) g_{L}(t)+a g_{F}(t)
$$

Erlang distribution function including exponential is applied to each of the probability density functions, $g_{L}(t)$ and $g_{F}(t)$, because it is relatively easy to handle in computations.

The probability density function of Erlang distribution is given as

$$
e(t)=(K \lambda)^{K} t^{K-1} \exp (-\lambda K t) /(K-1) ! \cdots
$$

and its mean $(M)$ and variance $(V)$ are

$$
M=1 / \lambda, V=M^{2} / K
$$

There is the relationship between mode $\left(M_{0}\right)$ and mean $(M)$ as

$$
M_{0}=M \times(K-1) / K
$$

The Erlang distribution applied to followers, headway can be estimated from the mode and the mean considering as follows: The modes are considered to be dominantly aflected by followers, because it seems to be caused by platoon forming that the modes are smaller than the mean. If we can consider that each of the followers drive at its own minimum safe headway and moreover, the capacity condition is the one where almost all vehicles become followers, the mean of the followers' headways may be always close to the headway at 


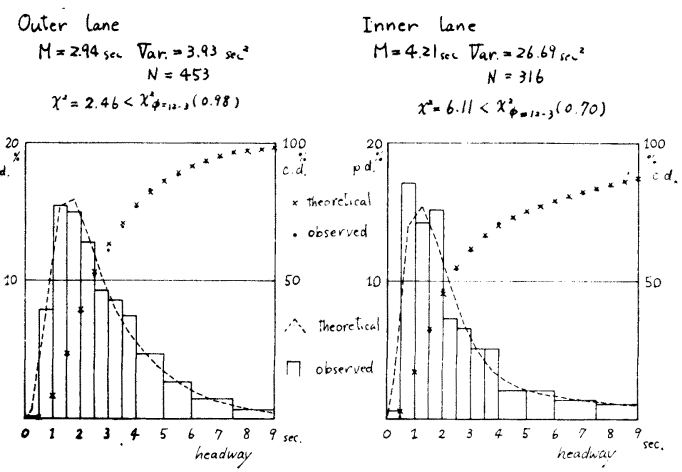

(a) MEISHIN EXPRESSWAY Downward

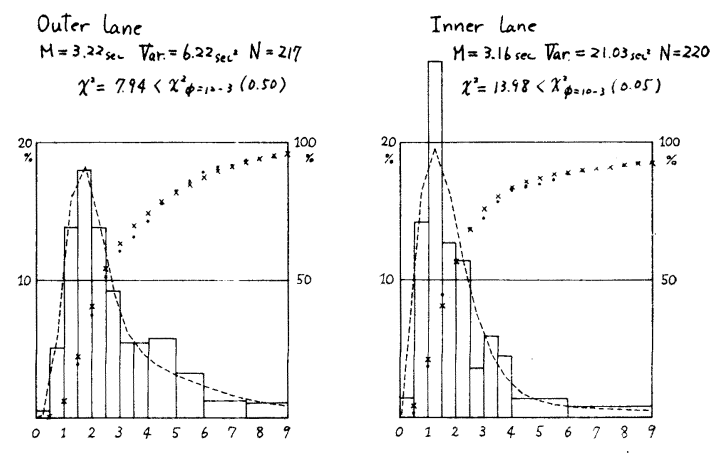

(b) TOKYO EXPRESSWAY ROUTE 1. Downward
Upward lane

$M=3.76$ se $\nabla_{\text {ar. }}=21.47 \& c^{\prime} N=365$

$x^{2}=11.80<x_{p=12-5}^{2}(0.20)$

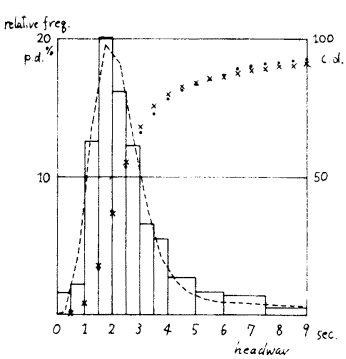

(c) NATIONAL ROUTE 14. (2-Lane Highway)
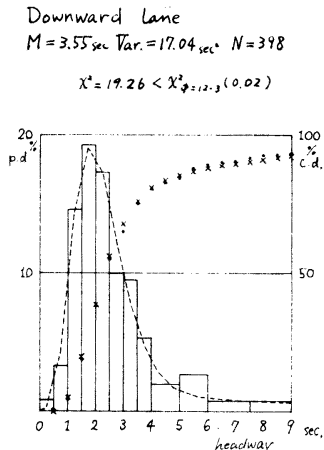
the capacity of the road. The mean of followers' headway may then be about 1.8 seconds which corresponds to 2000 vehicles/hour and the mode may be close the mode of actual headway distribution of all traffic flow.

As for the headways of leaders, if we assume free flow they may generally be of negative exponential distribution or phase 1 Erlang distribution. In the case of outer lane traffic, however, since their coefficients of variance are less than unity, Erlang distribution of phase 2 may be applied to them.

Truncated distribution have to be used for leaders' headways of both inner and outer lane traffic since the minimum headway is about 0.5 seconds as described in the preceding section. For the followers' headways, on the other hand, the minimum headway need not be considered just for simplicity of handling, since the Erlang distribution applied are of large phase number and probability density of the headway near origin is very small.

The parameters in the equation of theoretical distribution can then be determined and the two Erlang distribution are combined through the following steps adopting the characteristics of Erlang distribution shown in Eq. (5) and Eq. (6) :

(1) a) Presume the mean $\left(M_{F}\right)$ and phase $\left(K_{F}\right)$ of followers, within the range shown in (2).

b) Presume the minimum headway $\left(T_{L}\right)$ and the phase $\left(K_{L}\right)$ of leaders within the range shown in (2).

c) Using those values determine the mean headway $\left(M_{L}\right)$ of leaders and proportion of followers or platoon ratio, $a$, by solving the simultaneous equations below, which represent that the mean and the variance of theoretical composite distribution should coincide with those of the actual observed distribution.

$$
\begin{aligned}
& M_{F} a+M_{L}(1-a)=M \\
& \left(M_{F}{ }^{2}+V_{F}\right) a+\left(M_{F}^{2}+V_{L}\right)(1-a) \\
& =M^{2}+V
\end{aligned}
$$

where,

$M_{F}=$ mean of followers' headways

$V_{F}=$ variance of followers' headways

$M_{L}=$ mean of leaders' headways

$V_{L}=$ variance of leaders' headways

$M=$ mean of observed headways

$V=$ variance of observed headways

(2) The procedure mentioned above in (1) is repeated changing the constants $M_{F}, K_{F}, K_{L}, T_{L}$, with the range of the value shown in Table 3.

Table 3 The range of tested constant

\begin{tabular}{l|c|c|c|c}
\hline & $K_{F}$ & $M_{F}(\mathrm{sec})$ & $K_{L}$ & $T_{L}(\mathrm{sec})$ \\
\hline Outer lane & $5 \sim 13$ & $1.5 \sim 2.4$ & 1,2 & $0.5 \sim 0.8$ \\
Inner lane & $3 \sim 13$ & $1.2 \sim 1.8$ & $1, \quad 2$ & $0.4,0.5$ \\
Increment & 1 & 0.1 & 1 & 0.1 \\
\hline
\end{tabular}

(3) The best fitting theoretical distribution can be obtained through chi-square goodness-of-fit test with the observed data.

The procedures (1) through (3) were carried out by a computer. Table 4 shows the result of computations.

Figure 2 shows the observed distributions at various roads and the theoretical distributions for them. The broken lines in it show the best fitting theoretical probability density distribution obtained by the above procedures. The cumulative distributions are shown in it by $x$ for the theoretical distribution and by $\bullet$ for observed one. It could be said from the table and figure that the proposed theoretical distribution has good fittness to the actual headways.

For Tokyo Expressway Route 4, however, the proposed theoretical distribution did not fit well to the some part of the observed data. The reason may be that the traffic flow on the road did not seem consistent. There was an apparent decreasing trend in volume and was no consistent mean nor variance in the observation at Tokyo Expressway Route 4. Such falling trend and fluctuations are obvious in the Fig. 3 of 1 -minute flow fluctuation pattern. The shape of probability density function of proposed distribution, however, is still simillar to actual one even in such case.

\section{CONCLUSIONS AND SOME SUGGESTIONS FOR PRA- CTICAL APPLICATION}

The conclusions of the study can be summarized as follows.

1. Conclusions obtained from observed time headway distributions are shown in Table 5 .

a) The table shows that the modes and coefficients of variance are nearly constant, but there are differences between lanes when the density is below critical. The mode is about 0.9 to 1.1 seconds in the inner lane, and 1.5 to 1.7 seconds in the outer lane. The coefficients of variance are less than unity in the outer lane but larger than unity in the inner lane.

b) When the density is critical, however, no difference has been observed between lanes. The modes of headways are 1.2 to 1.4 seconds and coefficient of variance in the inner lane becomes also less than unity.

c) When the density exceeds critical the modes in both inner and outer lanes are 1.5 to 2.3 seconds, and the coefficients of variance become larger than unity for both lanes.

2. The minimum headway could be considered to 
Table 4 The Results of $\chi^{2}$ Goodness-of-fit Test

\begin{tabular}{|c|c|c|c|c|c|c|c|c|c|c|c|}
\hline \multirow{2}{*}{\multicolumn{2}{|c|}{ Road \& Lane }} & \multirow{2}{*}{$M$} & \multicolumn{3}{|c|}{ follower } & \multicolumn{3}{|c|}{ leader } & \multirow{2}{*}{$\chi^{2}$} & \multirow{2}{*}{ D.F. } & \multirow{2}{*}{$\begin{array}{l}\text { L.S. } \\
(\%)\end{array}$} \\
\hline & & & $K_{F}$ & $M_{F}$ & $a$ & $K_{L}$ & $M_{L}$ & $\tau_{L}$ & & & \\
\hline \multirow{2}{*}{$\begin{array}{l}\text { Meishin Expressway } \\
\text { Downward Outer lane }\end{array}$} & No. 1 & 2.94 & 5 & 1.7 & 0.302 & 2 & 3.46 & 0.5 & 2.46 & $12-3$ & 98 \\
\hline & No. 2 & 2.92 & 5 & 1.7 & 0.495 & 2 & 4.12 & 0.6 & 21.04 & $12-3$ & 1 \\
\hline \multirow{2}{*}{$\begin{array}{l}\text { Meishin Expressway } \\
\text { Upward Outer lane }\end{array}$} & No. 1 & 4.43 & 7 & 2.0 & 0.176 & 2 & 4.97 & 0.7 & 13.99 & $12-3$ & 10 \\
\hline & No. 2 & 4.28 & 5 & 2.2 & 0.429 & 2 & 5.84 & 0.5 & 15.71 & $12-3$ & 5 \\
\hline \multirow{2}{*}{$\begin{array}{l}\text { Meishin Expressway } \\
\text { Downward Inner lane }\end{array}$} & No. 1 & 4.21 & 3 & 1.7 & 0.511 & 1 & 6.83 & 0.5 & 6.11 & $12-3$ & 70 \\
\hline & No. 2 & 4.30 & 3 & 1.7 & 0.625 & 1 & 8.63 & 0.5 & 1615 & $12-3$ & 5 \\
\hline $\begin{array}{l}\text { Meishin Expressway } \\
\text { Upward Inner lane }\end{array}$ & $\begin{array}{l}\text { No. } 1 \\
\text { No. } 2\end{array}$ & 7.90 & 3 & 1.9 & 0.308 & 1 & 10.58 & 0.5 & 6.82 & $12-3$ & 50 \\
\hline \multirow{2}{*}{$\begin{array}{l}\text { Tokyo Expressway } \\
\text { Route1 Downward }\end{array}$} & \multirow{2}{*}{$\begin{array}{l}\text { Outer lane } \\
\text { Inner lane }\end{array}$} & 3.22 & 7 & 1.8 & 0.472 & 2 & 4.48 & 0.5 & 7.94 & $12-3$ & 50 \\
\hline & & 3.16 & 3 & 1.7 & 0.779 & 1 & 8.30 & 0.7 & 13.98 & $10-3$ & 5 \\
\hline \multirow{2}{*}{$\begin{array}{l}\text { Yokohama Bypass } \\
\text { Downward }\end{array}$} & \multirow{2}{*}{$\begin{array}{l}\text { Outer lane } \\
\text { Inner lane }\end{array}$} & 2.87 & 6 & 2.25 & 0.916 & 1 & 9.61 & 0.8 & 6.37 & $11-3$ & 50 \\
\hline & & 3.14 & 5 & 2.45 & 0.917 & 1 & 10.77 & 0.9 & 9.63 & $11-3$ & 25 \\
\hline \multirow{2}{*}{ National Route 14} & \multirow{2}{*}{$\begin{array}{l}\text { Downward } \\
\text { Upward }\end{array}$} & 3.55 & 5 & 2.25 & 0.753 & 1 & 7.51 & 0.8 & 19.26 & $12-3$ & 2 \\
\hline & & 3.76 & 6 & 2.25 & 0.744 & 1 & 8.15 & 0.7 & 11.80 & $12-3$ & 20 \\
\hline \multirow{3}{*}{$\begin{array}{l}\text { Tokyo Expressway } \\
\text { Route } 4 \text { Upwared } \\
\text { Outer lane }\end{array}$} & No. 1 & 1.83 & 9 & 1.75 & 0.964 & 2 & 3.97 & 0.5 & 4.51 & $9-3$ & 60 \\
\hline & No. 2 & 2.40 & 7 & 1.65 & 0.666 & 2 & 3.90 & 0.5 & 19.34 & $12-3$ & 2 \\
\hline & No. 3 & 2.60 & 9 & 1.55 & 0.487 & 2 & 3.60 & 0.5 & 7.88 & $9-3$ & 25 \\
\hline \multirow{3}{*}{$\begin{array}{l}\text { Tokyo Expressway } \\
\text { Route } 4 \text { Upwared } \\
\text { Inner lane }\end{array}$} & No. 1 & 1.59 & 15 & 1.58 & 0.998 & 2 & 3.47 & 0.5 & 13.51 & $6-3$ & rejected \\
\hline & No. 2 & 1.65 & 9 & 1.30 & 0.868 & 1 & 3.92 & 0.5 & 45.70 & $11-3$ & rejected \\
\hline & No. 3 & 1.97 & 7 & 1.40 & 0.770 & 1 & 3.89 & 0.5 & 12.84 & $8-3$ & 2 \\
\hline \multirow{2}{*}{$\begin{array}{l}\text { Tokyo Expressway Ring } \\
\text { Outer lane }\end{array}$} & No. 1 & 2.69 & 7 & 1.6 & 0.419 & 2 & 3.48 & 0.5 & 8.90 & $12-3$ & 30 \\
\hline & No. 2 & 2.65 & 7 & 1.7 & 0.453 & 2 & 3.44 & 0.5 & 7.14 & $12-3$ & 50 \\
\hline \multirow{2}{*}{$\begin{array}{l}\text { Tokyo Expressway Ring } \\
\text { Inner lane }\end{array}$} & No. 1 & 2.30 & 7 & 1.4 & 0.642 & 2 & 3.91 & 0.5 & 4.78 & $12-3$ & 80 \\
\hline & No. 2 & 2.10 & 7 & 1.5 & 0.763 & 2 & 4.03 & 0.5 & 30.30 & $11-3$ & rejected \\
\hline
\end{tabular}

D.F. $=$ Degree of Freedom ; L.S. $=$ Level of Significance

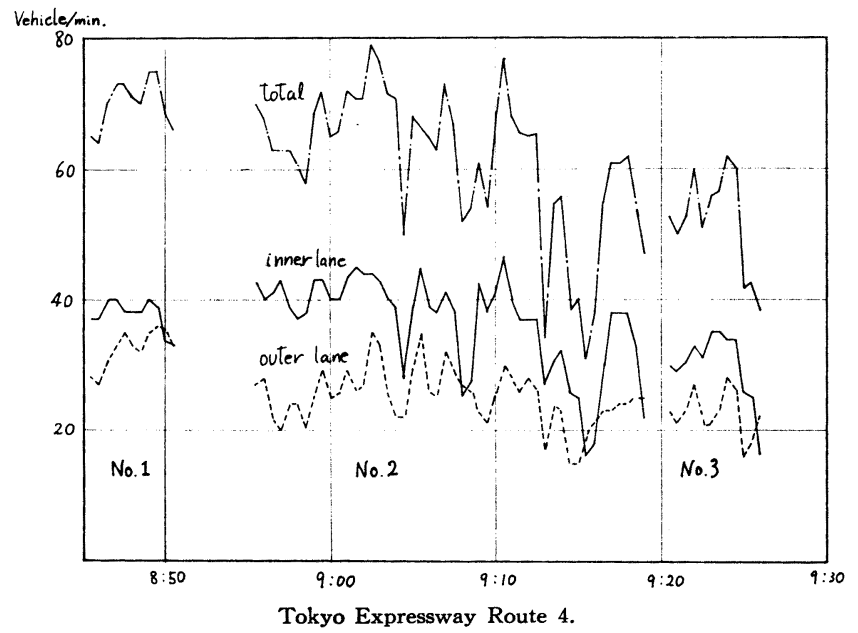

Fig. 3 Traffic Flow Pattern

Table 5 The Characteristics of Time Headway

\begin{tabular}{|c|c|c|c|c|}
\hline \multicolumn{2}{|c|}{ Traffic Flow Condition } & $\begin{array}{l}\text { Coefficients of } \\
\text { Variance }\end{array}$ & Mode & Roads Observed \\
\hline \multirow{2}{*}{$\begin{array}{l}\text { Under } \\
\text { Critical }\end{array}$} & Inner lane & over $1(1.2 \sim 1.3)$ & $0.9 \sim 1.1$ & \multirow{2}{*}{$\begin{array}{l}\text { Meishin Expressway } \\
\text { Tokyo Expressway }\end{array}$} \\
\hline & Outer lane & under $1(0.7 \sim 0.8)$ & $1.5 \sim 1.7$ & \\
\hline \multicolumn{2}{|c|}{$\begin{array}{c}\text { Critical } \\
\text { (Full Capacity) }\end{array}$} & under $1(0.3 \sim 0.8)$ & $1.2 \sim 1.4$ & $\begin{array}{c}\text { Tokyo Expressway } \\
\text { Route } 4\end{array}$ \\
\hline \multicolumn{2}{|c|}{ Over Critical Density } & over 1 (about 1.1 ) & $1.5 \sim 2.3$ & Yokohama Bypass \\
\hline
\end{tabular}


be about 0.5 seconds.

3. A theoretical headway distribution which fits well to the observed distribution can be given as a composite Erlang distribution in which the parameters can be determined easily by the procedures mentioned in the preceding section.

4. Almost same parameters are obtained from various observations when traffic conditions are in the same domain, as shown in Table 6 .

a) When density is below critical, the mean of followers' headways is about 1.7 to 2.0 seconds and phase number $K$ of Erlang distribution is about 5 to 7 for either outer lanes of 4-lane highways or 2-lane highways and about 3 for inner lanes of 4lane highways.

Truncated Erlang distribution can be applied to leaders' headways. The phase $K=1$ is well fitted to inner lanes of 4-lane highways and 2-lane highways and $K=2$ to outer lanes of 4-lane highways.

b) At critical density, Erlang distribution of phase $K=7$ to 10 and of which mean is 1.4 to 1.7 seconds fits well to the followers' headways. The same distribution as mentioned in a) for below critical condition could be applied to leaders' headways.

c) When density exceeds critical, the phase number $K$ of Erlang for followers' headways is about 6 and the mean may be 2.3 to 2.5 seconds. The negative exponential distribution truncated below 0.8 to 0.9 seconds might be applied to leaders' headways.

The following suggestions may be usefull for practical applications of the proposed theoretical distributions as input data.

a) The mean and variance of time headways and the phase number of Erlang have to be given. The mean can easily be obtained by the inverse of traffic flow rate, which is most common parameters of traffic flow condition. When the variance is not given, Table 5 can be used to estimate the variance based on the mean value since the table lists the coefficients of variance in various traffic conditions. The phase number of Erlang can be estimated reffering to Table 6 in accordance with the traffic

Table 6 The Parameters of the Theoretical Distribution

\begin{tabular}{|c|c|c|c|c|c|}
\hline \multicolumn{2}{|c|}{ Traffic Flow Condition } & $\begin{array}{c}M_{F} \\
(\mathrm{sec})\end{array}$ & $K_{F}$ & $K_{L}$ & ${ }^{\tau} L$ \\
\hline \multirow{2}{*}{$\begin{array}{l}\text { Under } \\
\text { Critical }\end{array}$} & Inner lane & \multirow{2}{*}{$1.7 \sim 2.0$} & 3 & 1 & 0.5 \\
\hline & Outer lane & & $5 \sim 7$ & 2 & 0.5 \\
\hline \multicolumn{2}{|c|}{$\begin{array}{c}\text { Critical } \\
\text { (Full Capacity) }\end{array}$} & $1.4 \sim 1.7$ & $7 \sim 10$ & 1,2 & 0.5 \\
\hline \multicolumn{2}{|c|}{ Over Critical } & $2.3 \sim 2.5$ & $5 \sim 6$ & 1 & $0.8,0.9$ \\
\hline
\end{tabular}

conditions.

b) The length of time during which the same distribution can be applied must be carefully deter- mined. When traffic volume is in increasing or decreasing trend, the mean of headways is not consistent and the distribution should be changed at a certain interval.

\section{ACKNOWLEDGEMENT}

The author would like to express his sincere appreciation to Prof. Hoshino and Associate Prof. Koshi of Tokyo University for their guidances and helpful suggestions. The author also would like to thank Prof. Watanabe of Tokyo Institute of Technology for his critical reading of this paper.

\section{APPENDIX}

Probability Density Function of a Compound Distribution

Probability density function of the headway distribution as the combination of two different traffic flow can generally be represented in the following.

$$
g(t)=(1-a) g_{L}(t)+a g_{F}(t) \cdots \cdots \cdots \cdots \cdots(1)
$$

where,

$g(t)=$ probability density function of time headways of all traffic

$g_{L}(t)=$ probability density function of headways of free-moving vehicles (leaders)

$g_{F}(t)=$ probability density function of headways of constrained vehicles (followers)

$a=$ proportion of constrained group in the total traffic.

This equation can be induced from the probability of vehicle arrivals as follows.

When total traffic flow rate be $Q$ and the proportion of followers be $a$, then the flow rate of followers is $Q a$ and the proportion of leaders is $Q(1-a)$. The probability that no vehicles arrive in arbitrary interval $\theta$ is defined as follws.

$$
\begin{aligned}
P_{0}(\theta) & =\text { Prob. (no vehicles arrival in } \theta) \\
P_{L_{0}}(\theta) & =\text { Prob. (no leaders arrival in } \theta) \\
P_{F_{0}}(\theta) & =\text { Prob. (no followers arrival in } \theta \text { ) }
\end{aligned}
$$

Since the probability that arbitrary $\theta$ exists in the gaps of leaders is $(1-a) Q \bar{t}_{L}$, and the one of followers is $a Q \bar{t}_{F}$,

$$
P_{0}(\theta)=(1-a) Q t_{L} P_{L 0}(\theta)+a Q t_{F} P_{F_{0}}
$$

where

$\bar{t}_{L}=$ the mean headway of leaders

$\bar{t}_{F}=$ the mean headway of followers

The probability density function of the gap from arbitrary point to next arrival point is different from the one of the gap between successive arrival points and is called the starting density function. If mean gap size is $\bar{t}$ and cumulative distribution function is $G(t)$, then the starting density function $g_{0}(t)$ is

$$
g_{0}(t)=(1-G(t)) / \bar{t} \cdots \cdots \cdots \cdots \cdots \cdots \cdots \cdots \cdots \cdots \cdots \cdots \cdots \cdots \cdots(3)
$$


The probability $P_{0}(\theta)$ that no arrival in $\theta$ can be written as

$$
\begin{aligned}
P_{0}(\theta) & =\text { Prob. (no arrival in } \theta) \\
& =\text { Prob. (starting gap }>\theta) \\
& =\int_{\theta}^{\infty} g_{0}(t) d t=\int_{\theta}^{\infty}(1-G(t)) / \bar{t} \cdot d t \cdots(4)
\end{aligned}
$$

Differenciating this equation with two times, following relation is obtained

$$
g(\theta)=\bar{t} \frac{d^{2}}{d \theta^{2}} P_{0}(\theta)
$$

Differenciating Eq. (2),

$$
P^{\prime \prime}(\theta)=(1-a) Q \bar{t}_{L} P_{L_{0}}{ }^{\prime \prime}(\theta)+a Q \bar{t}_{F} P_{F_{0}}{ }^{\prime \prime}(\theta)
$$

$$
\text { .......................... (6) }
$$

Substituting Eq. (5) into this equation,

$$
1 / \bar{t} \cdot g(\theta)=(1-a) g_{L}(\theta) Q+a Q g_{F}(\theta)
$$

and because of $1 / \bar{t}=Q$

$$
g(\theta)=(1-a) g_{L}(\theta)+a g_{F}(\theta)
$$

We have thus obtain the equation (1) and of course relationships between the means is

$$
\bar{t}=\int_{0}^{\infty} t g(t) d t=(1-a) \bar{t}_{L}+a \bar{t}_{F}
$$

\section{Refereces}

1) Highway Research Board: "Highway Capacity Manual 1965”, National Academy of Sciences, pp. 4959, 1965.

2) P.C. Pac-Poy: "The Use and Limitation of the
Poisson Distribution in Road Traffic", Australian Road Research Board, Second Conference, Vol. 2, 1964.

3) Russel M. Levis : "A Proposed Headway Distribution for Traffic Simulation Studies", Traffic Eng., Vol. 33, pp. 16-19, Feb. 1963.

4) R.M. Oliver and B. Thivault : "A High-Flow TrafficCounting Distribution", Highway Research Board Bulletin 356, pp. 15-27.

5) Adams, W.F. : "Road Traffic Considered as a Random Series", J. of the Inst. of Civil Eng., Vol. 4, pp. 121-130, Nov. 1936

6) Gerlough, D.L. : "Traffic Inputs for Simulation on a Digital Computer", Proc. of Highway Research Board, Vol. 38, pp. 480-492, 1959.

7) Frank A. Haight : "Mathematical Theories of Traffic Flow”, Academic Press, pp. 103-104, 1963.

8) Martin Wohl and B.V. Martin : "Traffic System Analysis”, pp. 352-362, McGraw-Hill. 1967.

9) Schuhl, A. : "The Probability Theory Applied to Distribution of Vehicles on Two-Lane Highways", Poisson and Traffic, Eno Foundation for Highway Traffic Control, pp. 59-75, 1955.

10) Reference 1) p. 56, Fig. 3.33.

11) Reference 7) pp. 111-114.

12) Hiroshi Takada : "Application of Computer Simulation Techniques to Road Traffic Analysis", Trans. of the J.S.C.E., No. 124, pp. 28-41, Dec. 1965 (in Japanese).

(Received Aug. 28, 1970) 